\title{
Hooded Ladies' Tresses
}

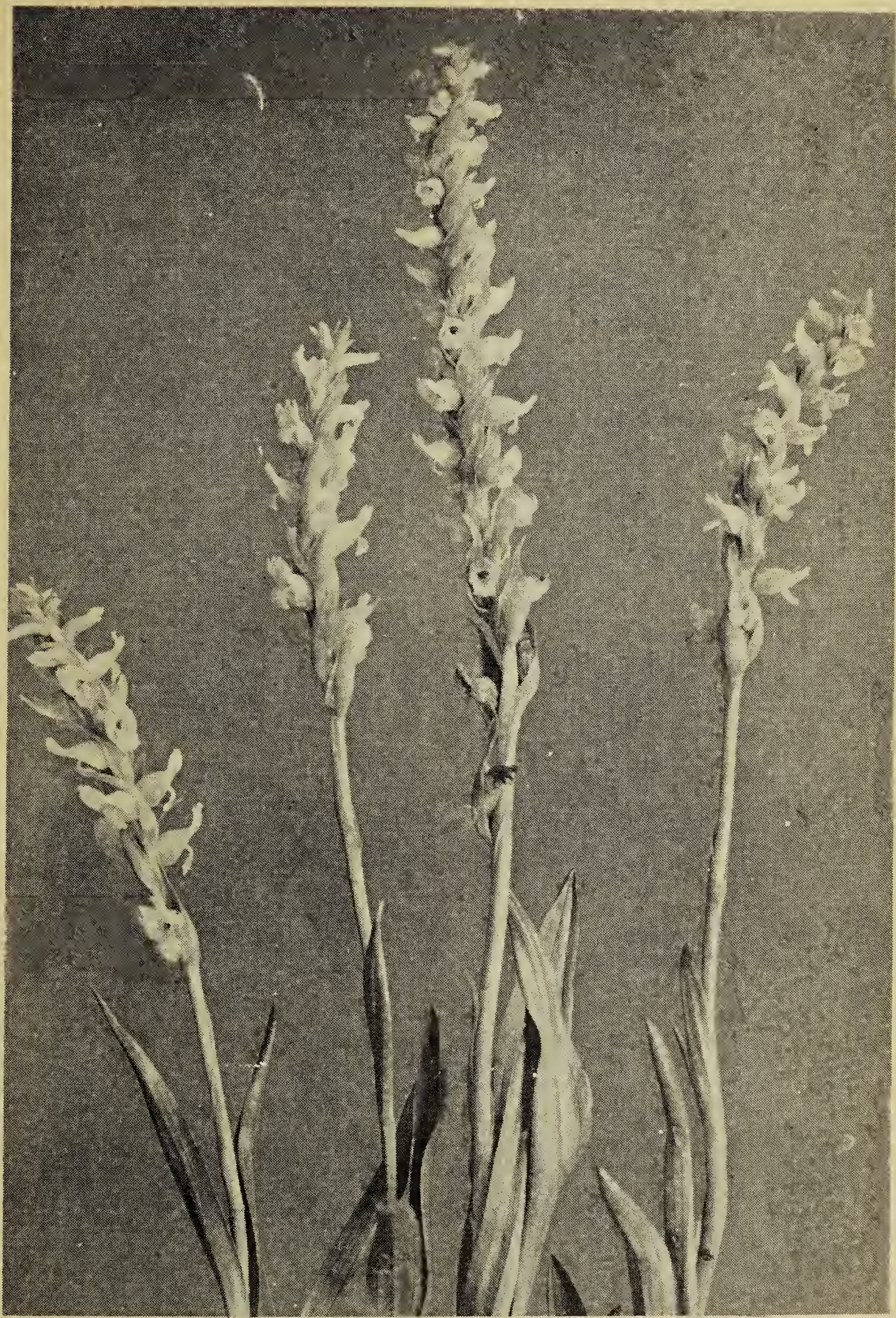

Photo by W. C. McCalla

Spiranthes romanzoffians Cham. \& Schl.

The Hooded Ladies' Tresses is a species of wide distribution in Canada. It is found from Newfoundland and Nova Scotia to British Columbia and Yukon. It is the most northern member of its genus and it is the only member of the Orchid Family found in Northern Saskatchewan by G. W. Scotter in the following article. It grows in bogs and wet meadows. The flowers are white and sweet-scented. 